\title{
Stimulate Engagement and Motivation in MOOCs Using an Ontologies Based Multi- Agents System
}

\author{
Abderrahim El Mhouti \\ Abdelmalek Essaadi University, Faculty of Sciences/LIROSA laboratory, Tetouan, Morocco \\ E-mail: abderrahim.elmhouti@gmail.com \\ Azeddine Nasseh and Mohamed Erradi \\ Abdelmalek Essaadi University, Ecole Normale Supérieure/LIROSA laboratory, Tetouan, Morocco
}

\begin{abstract}
Today, Massive Open Online Courses (MOOCs) have the potential to enable free online education on an enormous scale. However, a concern often raised about MOOCs is the consistently high dropout rate of MOOC learners. Although many thousands of learners enroll on these courses, a very small proportion actually complete the course.

This work is at the heart of this issue. It is interested in contributing on multi-agents systems and ontologies to describe the learning preferences and adapt educational resources to learner profile in MOOCs platforms. The primary aim of this work is to exploit the potential of multi-agents systems and ontologies to improve learners' engagement and motivation in MOOCs platforms and therefore reduce the drop-out rates.

As part of the contribution of this work, the paper proposes a model of Multi-Agent System (MAS), based on ontologies for adapting the learning resources proposed to a learner in a MOOCs platform according to his learning preferences. To model an adequate online course, the determination of learner's preferences is done through the analysis of learner behavior relying on his indicator MBTI (Myers Briggs Type Indicator). The proposed model integrates the main functionalities of an intelligent tutoring system: profiling, updating of the profile, selection, adaptation and presentation of adequate resources. The architecture of the proposed system is composed on two main agents, four ontologies and a set of modules implemented.
\end{abstract}

Index Terms-MOOC, drop-out, Multi-agent System, adaptation, ontologies, engagement, motivation.

\section{INTRODUCTION}

Today, Massive Open Online Courses (MOOCs) represent a real technological revolution in opening knowledge and ways of teaching and learning. Since their appearance in 2008, MOOCs are used as open spaces where teaching pedagogy is based on the use of free resources. The main objectives are to make available the knowledge more openly through quality learning content and to create and enrich the course with new knowledge and tools through the interactions of various users.

MOOCs are a relatively new model for the delivery of online learning to students. As "massive" and "open", these courses are intended to be accessible to many more learners than would be possible through conventional teaching. They are often free of charge and participation need not be limited by the geographical location of the learners [1] [2].

However, despite their rapid development, the educational potential of MOOCs suffers limitations that hinder their development in the distance learning field. Indeed, if MOOCs have been very successful mainly due to their innovative nature in the way of learning, the major problems related to their use are emerging in the first place the very high drop-out rate, which may prove to be one of the major reasons of the problems in learning based MOOCs. In this context, many studies have shown that tracking rates are a misleading indicator of the success of a MOOC and the low completion rate of these courses is sometimes due to a lack of efficiency, often linked to the problem of individualization, quality of content and the lack of personal attention [3] [4] [5] .

This work is a contribution to the research efforts on the obstacles and challenges faced by learners within MOOCs and specifically addresses issues related to the high drop-out rate in these open online courses. Thus, to promote the behavior of engagement and motivation of learner, this work aims to propose new methods, based on adaptation of educational content to the learner profile using Multi-Agents Systems (MAS) and ontologies, to obtain courses tailored to the needs of each learner.

The paper is organized as follows: firstly, this paper reviews existing literature relating to MOOCs and their development and focuses mainly on issues relating to MOOC drop-out rates and reasons of this drop-out. The paper presents also basic concepts related to the process of profiling and educational contents adaptation, particularly, multi-agents systems, ontologies and MBTI technique. The article goes on to provides suggestions to reduce the drop-out rate in MOOCs. Thus, this work consists to equip MOOCs platforms with a MAS based on ontologies and tools to help to identify learner profile 
by integrating learner model and content adaptation concepts in order to promote engagement and motivation of such learners. Finally, the paper proceeds to describe the proposed architecture to implement the framework and concludes with future works.

\section{RESEARCH BACKGROUND}

Massive Open Online Courses have received wide publicity and many institutions have invested considerable effort in developing, promoting and delivering such courses. However, there are still many unresolved questions relating to MOOCs and their effectiveness. One of the major recurring issues raised in academic literature is the consistently high drop-out rate of MOOC learners. Although many thousands of participants enroll on these courses, the completion rate for most courses is below $13 \%$ [6].

This section presents the concept of MOOC and reviews issues relating to MOOCs drop-out, considering published data on MOOCs completion and discussing factors implicated in previous studies as being related to attrition. On the other hand, this section describes basic concepts on which the proposed courses adaptation system is based, such as: profiling, content adaptation, Multi-Agents Systems, ontologies and the MBTI tool for describing learning styles.

\section{A. MOOCs}

\section{Overview}

A Massive Open Online Course (MOOC) is an online course aimed at unlimited participation and open access via the web. In addition to traditional course materials such as filmed lectures, readings, and problem sets, many MOOCs provide interactive user forums to support community interactions between students, professors, and teaching assistants. MOOCs are a recent and widely researched development in distance education which was first introduced in 2008 and emerged as a popular mode of learning in 2012 [7][8][9]. Two key features characterize this new educational technology: open accessibility and scalability. Thus, MOOC participants do not need to be registered in a school or a university nor paying fees in order to take part of a MOOC.

Early MOOCs often emphasized open-access features, such as open licensing of content, structure and learning goals, to promote the reuse and remixing of resources. Some later MOOCs use closed licenses for their course materials while maintaining free access for various participants.

On the other hand, MOOCs can be seen as a term or word related to the scalability of open and online education. They are a recent development in the area of distance education, and a progression of the kind of open education ideals suggested by open educational resources [9]. MOOCs were perceived by Stephen Downes, and George Siemens, as an approach to address information excess, react to students' inquiries for pertinent knowledge, integrate technologies progress, and decrease education's fee [10]. The intended objectives of this suggested online educational model was to gather unlimited number of learners, course materials, and information transfer means. The proposed model would not be subject to any limitations except for technological capabilities and their related costs. While MOOCs are considered a relatively new initiative, the concept was first discussed in 2008, but wasn't really taken up to any great extent until the last couple of years. The term MOOC (Massive Open Online Course) was coined by Dave Cormier and created a buzz in 2012 which has already been described as the year of the MOOC [11].

In more detail, the table 1 presents the different dimensions of a MOOCs [12].

Table 1. Criteria of different dimensions of a MOOC [12]

\begin{tabular}{|c|c|c|c|}
\hline & & Dimension definition of MOOC & Criteria deciding for a MOOC \\
\hline M & Massive & $\begin{array}{l}\text { An online course designed for large number } \\
\text { of participants }\end{array}$ & $\begin{array}{l}\text { Number of participants is larger than can be taught in a } \\
\text { 'normal' campus class room / } \\
\text { college situation }(>150)\end{array}$ \\
\hline O & Open & $\begin{array}{l}\text { Course can be accessed by } \\
\text { (almost) anyone anywhere as long as they } \\
\text { have an internet connection }\end{array}$ & $\begin{array}{l}\text { - Course accessible to (almost) all people without } \\
\text { limitations. } \\
\text { - At least the course content is always accessible. } \\
\text { - Course can be accessed anywhere as long as they } \\
\text { have an internet connection }\end{array}$ \\
\hline $\mathbf{O}$ & Online & Complete course online & All aspects of course are delivered online \\
\hline C & Course & Unit of Study & $\begin{array}{l}\text { The total study time of a MOOC is minimal } 1 \text { ECTS } \\
\text { (typically between } 1 \text { and } 4 \text { ECTS) }\end{array}$ \\
\hline
\end{tabular}

Indeed, there are two types of courses offered through the MOOCs platforms: cMOOCs and XMOOCs [13]. The first type [11], described as the good MOOCs by George Siemens, who, with Stephen Downes, early put forward these courses in Canada, is essentially based on a philosophy of connectedness and sustains the social dimension of learning and active practices; thereby, this type of course encourages knowledge production rather than knowledge consumption. While xMOOCs, the most adopted by higher education worldwide, consider the instructor-guided lesson as the center of the course and offer to large numbers of students the opportunity to study high quality courses with prestigious universities. Table 2 analyses and gives an overview of the different forms of MOOCs in terms of massive, open, online and course [14]. 
Table 2. MOOC Typologies [14]

\begin{tabular}{|c|c|c|}
\cline { 3 - 3 } xMOOCs & Massive & $\begin{array}{c}\text { Community and } \\
\text { connections }\end{array}$ \\
\hline $\begin{array}{c}\text { Open access-Restricted } \\
\text { license }\end{array}$ & Open & Open access \& license \\
\hline $\begin{array}{c}\text { Individual learning in } \\
\text { single platform }\end{array}$ & Online & $\begin{array}{c}\text { Networked learning } \\
\text { across multiple platforms } \\
\text { and services }\end{array}$ \\
\hline $\begin{array}{c}\text { Acquire a curriculum of } \\
\text { knowledge \& skills }\end{array}$ & Course & $\begin{array}{c}\text { Develop shared practices, } \\
\text { knowledge and } \\
\text { understanding }\end{array}$ \\
\hline
\end{tabular}

A MOOC system is consisted of five main elements: Instructors, learners, topic, material, and context [15]:

- Instructors: simplify the learning process via making available appropriate material, initiate communication between learners, and manage evaluations with regards to intended learning outcomes.

- Learners: anyone who wants to learn about the topic. Learners could be pursuing a formal degree or not. Learners who are simply interested with no precise objective are as well authorized to enroll.

- Topic: it is discovered through the learner, instructor, material, and context. It is introduced all over the learning system and not just residing in a warehouse. Topic is adequately limited to allow emphasis but adequately wide to provide extensive coverage.

- Material: resides in diverse sites and is accessed via various technological solutions.

- Context: represents the different actors forming a learning environment. This can incorporate online social networks, IT solutions, conventional information origins, diverse kinds of information transfer schemes, communication systems, intended learning outcomes, and the group constituting every course offering.

In MOOCs platforms, information provided to learners is considered starting points from which they can jump off and pursue an information trajectory in accordance with their concerns. Accordingly, learners are able to communicate with one another through forums set up to help them discover common fields, find help and extra materials, and constitute particular groups so as to investigate shared topics more thoroughly. Indeed, the objective is to conceive a community of learners whereby everyone contributes by information and perspectives besides those provided by the instructor, and to get in an exploration ride.

A course offered through a MOOC platform can be subject to a predefined time schedule or not, and can incorporate videos of different sources, links to websites and other online resources, some extra study materials, support forums, and all this can be accessed through multiple devices connected to the internet [10][11]. The learner chooses through which mean information is transferred may it be class forums, online social networks, or any other virtual domain. The strongest feature of a MOOC platform is elasticity [15].

\section{MOOC drop-out and completion}

Despite the great enthusiasm for and rapid growth of MOOC courses and platforms, there has also been rising concern over a number of MOOC aspects. One feature in particular that is difficult to ignore is that these massive courses also have massive drop-out rates [3][4]. As noted by Kolowick: "massive open online courses have gained renown among academics for their impressive enrolment figures and, conversely, their unimpressive completion rates" [5].

Few MOOCs have a percentage completion, which reaches double figures [4]. Of the millions of learners who have already participated in MOOCs, the vast majority do not get to the stage of obtaining a certificate of completion. This is seen by some as "an indictment of the MOOC format" [5] and Devlin has noted commentators in this camp "hinting that therein lies a seed of the MOOC's eventual demise" [16]. However, the counterargument holds that completion rate statistics should not be viewed in this way. If even a small percentage of a very large group completes, the actual number of successful students will still be far greater than would otherwise have been possible. A number of authors point out that the bare figures do not provide a realistic view of the situation and suggest the need for a new metric. It is claimed that courses on the Coursera platform have a $45 \%$ completion rate if only those students who reach at least the first assessment are included [16]. This rises to $70 \%$ for students on the "Signature Track" scheme (for which a $\$ 50$ payment is required) [6]. Devlin also argues that a fairer comparison would be with the numbers who apply for entry to traditional university courses [16].

\section{Reasons for drop-out}

There are many reasons for student drop-out. These reasons range from the absence of the real intention to the peer review. In this section, we present the main reasons cited in the research work related to the completion rate in MOOCs platforms [6]:

- No real intention to complete: a number of authors have noted that reasons for participation given by users often include motivations such as "out of curiosity" and "to learn more about MOOCs" rather than to learn the subject itself [5]. It is therefore suggested that many enrolments are from people who do not intend to participate fully, including professionals who want to gain understanding of the format in order to produce their own courses [17].

- Lack of time: students who fully intend to complete the course may fail to do so because they are unable to devote the necessary time to study. This has been noted even in courses where participants have a high level of motivation to complete. 
- Course difficulty and lack of support: related to the previous point is the level of difficulty of a course and the lack of necessary background.

- Educational content not adapted to learner profile: learners who are intend to complete the course may fail to do so because the educational content delivered is not adapted to their profile of learning. These include: not adapted learning, contents and services not suitable to the learner preferences, inappropriate learning experience, no customization of the instruction to the learner.

- Lack of digital skills or learning skills: online learning generally requires a high degree of autonomy and depends on users being able to work with the technologies and formats used. Even those who are familiar with using a range of everyday technologies may be uncomfortable when new systems must be quickly mastered.

- Bad experiences: some MOOC participants have pointed to a variety of bad experiences as being a barrier to continued participation. These include: inappropriate behavior of peers in forums; lack of focus and coordination in forums; depletion of study groups due to attrition; poor quality and incorrect learning materials; technical problems in the MOOC platform.

- Expectations: students may enroll with little understanding of what the course requires and may have unrealistic expectations either of the course or of their own ability to undertake it.

- Starting late: late starters on a course may find it very difficult to catch up and outcomes are likely to much lower for this group of students [18]. It is not simply a matter of catching up with learning materials.

- Peer review: some authors have noted that courses relying on peer grading often have much lower completion rates than others [3][4]. Peer grading may well require more work on the students' part. It has also been suggested that some students are unhappy with the concept of peer review and that training is often lacking [19]. Other participants have been disheartened by bad practice discovered through peer review.

\section{B. Adaptation of learning contents to learners profiles based on Multi-Agents systems}

Adaptive learning systems are designed to align learning sequences and learner profiles. They use, for this purpose, one or more models to represent knowledge. In this context, the techniques of artificial intelligence are used for modeling of learners and the adaptation of teaching sequences. The objective is to provide the learner, at any time, relevant information presented in an appropriate manner [20]. These adaptive systems have the ability to adjust the educational content to each learner by analyzing the information collected and the actions of learners.
With the evolution of educational technology, several models and prototypes of adaptive educational web based systems have emerged: smart education systems, multiagent systems (MAS), Intelligent Tutoring System (ITS), Adaptive Hypermedia Systems (AHS), etc. These systems are the result of crossing research on intelligent and adaptive hypermedia systems.

In this work, the adaptation of educational content to the learner profile is based on a Multi-Agent System (MAS). A MAS is a society of intelligent agents in which each agent acts autonomously in a goal oriented manner to achieve the final goal of the system [21]. Multi-agents systems are the application of artificial intelligence the most famous. These systems are used in various areas, one such area is the online learning and training. The idea to implement an education system by a multi-agents systems is not new but is still young. Many online and elearning systems are realized using the multi-agents architecture as: BAGHERA [22], GD.Visu@1 [23], SIOF [24], OPUS One [25], etc. Most of these systems generates courses based on the model of the learner.

The methods and techniques of content adaptation vary considerably from one system to another. As part of this work, the proposed multi-agent system to adapt learning content to learner profile is based on the use of ontologies and the MBTI (Myers Briggs Type Indicator) method for the description of learning preferences. In the next two sections, this paper presents these two concepts on which is based the proposed model of MAS.

\section{Ontologies and education systems}

\section{Contributions of ontologies in online learning}

In the domain of e-learning and distance online courses, the contribution of ontologies in the design of adaptive learning systems has been amply demonstrated. These ontologies were the basis of navigation offering forms of acquisition other than those proposed in the course of classical learning which are generally linear type. They are also used as part of an educational approach based on collaborative writing for the structuring of hyper-books and making inferences [26].

In an adaptive learning system (ITS, MAS, etc), the use of ontologies is quite appropriate because it allows better interoperability and data exchange. Ontologies are also used for searching and indexing various educational resources [27].

\section{Ontologies and "profiling"}

In the context of adaptive learning systems, ontologies represent a solution to describe the learning preferences of the learners: "profiling".

Profiling is the activity which consists on analyzing the behavior of a learner in order to deduce his profile. The profile is considered as a set of data which modelize certain characteristics of the learner [28].

In an adaptive learning system, the activity of profiling consists on defining the values of the manipulated elements by the various models, such as: the knowledge model and the learner model. In this context, several 
studies have developed models for the representation of knowledge of learners. Some authors advocate the use of different ontologies for each of these models [29][30][31][32].

This work proposes an approach based on ontologies for describing learners profiles, and more specifically for the representation of styles (learner preferences) of learning in a MOOCs platform. The used ontologies are implemented in a Multi-Agents system. To do this, the proposed approach uses the tool MTBI (Myers Briggs Type Indicator) to describe these learning preferences.

\section{MBTI tool for describing learning preferences}

The MBTI (Myers Briggs Type Indicator) is a model of psychological assessment determining the psychological type of a subject, following a method proposed in 1962 by Isabel Briggs Myers and Katherine Cook Briggs. It serves as a tool in the identification of psychological dominant of persons in contexts related to management or to the problems in the context of interpersonal relationships. This model is based on the theory of psychological types of MBTI and directly inspired the theory of psychological types of Carl Gustav Jung [33].

The MBTI describes with finesse the functioning of the person highlighting preferences spontaneous concerning four dimensions. Each dimension has two opposite poles. Fig. 1 shows the four dimensions of the MBTI personality.

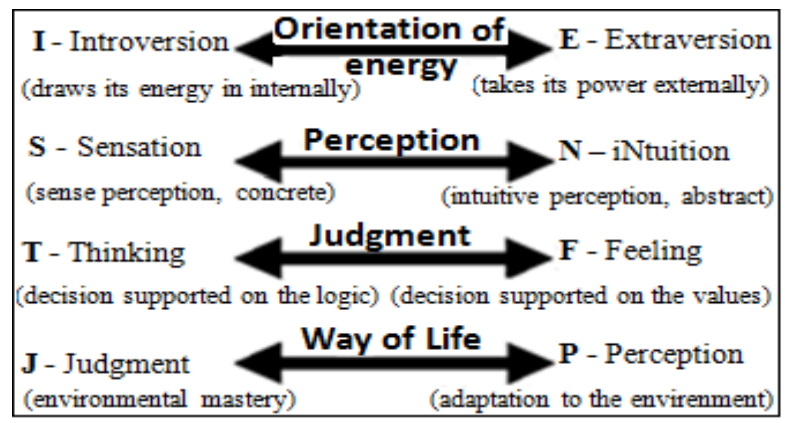

Fig.1. The four dimensions of the MBTI personality

Table 3. Main characteristics of each MBTI preference

\begin{tabular}{|c|c|}
\hline $\begin{array}{l}\text { Extraversion } \\
\text { Prefers brining energy outside } \\
\text { oneself, at others. }\end{array}$ & $\begin{array}{l}\text { Introversion } \\
\text { Prefers getting energy from the } \\
\text { inside world of ideas, emotions, } \\
\text { feelings. }\end{array}$ \\
\hline Sensing & Intuition \\
\hline $\begin{array}{l}\text { Prefers concentrating on the } \\
\text { information obtained from the } \\
\text { five senses and the practical } \\
\text { applications. }\end{array}$ & $\begin{array}{l}\text { Prefers concentrating on the } \\
\text { structure, the rapports and the } \\
\text { possible meanings. }\end{array}$ \\
\hline Thinking & Feeling \\
\hline $\begin{array}{l}\text { Prefers making decisions based } \\
\text { on logic and en the objective } \\
\text { analysis of causes and effects. }\end{array}$ & $\begin{array}{l}\text { Prefers making decisions based } \\
\text { on appreciation progress, and } \\
\text { taking into consideration what } \\
\text { is important for people. }\end{array}$ \\
\hline Judging & Perceiving \\
\hline $\begin{array}{l}\text { Appreciates a planned and } \\
\text { organized approach to life. It } \\
\text { prefers decisions- making. }\end{array}$ & $\begin{array}{l}\text { Appreciates a flexible and } \\
\text { spontaneous approach, and } \\
\text { prefers keeping options. }\end{array}$ \\
\hline
\end{tabular}

The characteristics of each MBTI model preference are described in Table 3.

Combining poles of different dimensions (E-I, S-N, TF, J-P), the MBTI indicator allows to distinguish sixteen psychological types (Table 4)[34].

Table 4. The 16 psychological types of MBTI [33]

\begin{tabular}{|l|c|c|c|}
\hline INTP & INFP & ISTP & ISFP \\
\hline INTJ & ENFP & ISTJ & ISFJ \\
\hline ENTJ & INFJ & ESTP & ESFP \\
\hline ENTP & ENFJ & ESTJ & ESFJ \\
\hline
\end{tabular}

According to the theory of psychological types, each has a natural preference for one of opposite poles of each of the four dimensions. When someone uses his preferred pole, it generally succeeds better and it feels more competent, natural and dynamic. Generally speaking, when they tackle new or difficult topics, students learn easily when they have the opportunity to use their preferred learning style.

\section{AN ONTOLOGIES BASED Multi-AgENTS SYSTEM TO INTEGRATE INTO MOOCS PLATFORMS}

In MOOCs platforms, reduce the drop-out rates of learners is not always so easy because one of the difficulties when arranging these platforms can be that the courses and learning paths offered are not adapted to learners profiles. However, one way to reduce these problems and promote engagement and motivation of learner to complete courses where they are registered is to adapt these courses and contents to her/his profile.

For that purpose, this paper proposes a methodology for the adaptation of online courses delivered by MOOCs platforms. The process of adaptation is assured by a Multi-Agents System, a system designed to be integrated in MOOCs platforms. The system is implemented using ontologies and the process of profiling rests on MBTI indicator of learners.

This section defines and explains the foundations on which rests the proposed multi-agents system. Then, current section continues by describing the conceptual architecture, ontologies and agents adopted to implement the system. The process of functioning of the model is also presented.

\section{A. Ontologies implemented}

The proposed model of MAS has four main ontologies: Learner, Resource, Domain, and Strategy of teaching/learning. Each ontology is composed of several sub-ontologies (simplified ontologies). The four ontologies are interconnected and can describe the two main models of the adaptive teaching/learning: Pedagogical model and Domain of knowledge model.

\section{Learner ontology}

The "Learner" model is defined as an ontology $\mathrm{O}_{\text {Learner }}$ which comprises various characteristics of a participant of MOOC. This work proposes to describe a MOOC 
participant (learner) in four levels. These levels are described as Sub-Ontologies $(\mathrm{SO}): \mathbf{O}_{\text {Learner }}=\left\{\mathbf{S O}_{\text {Identity }}\right.$, SOPreferences, SOCapacity, SOHistory (Fig. 2).

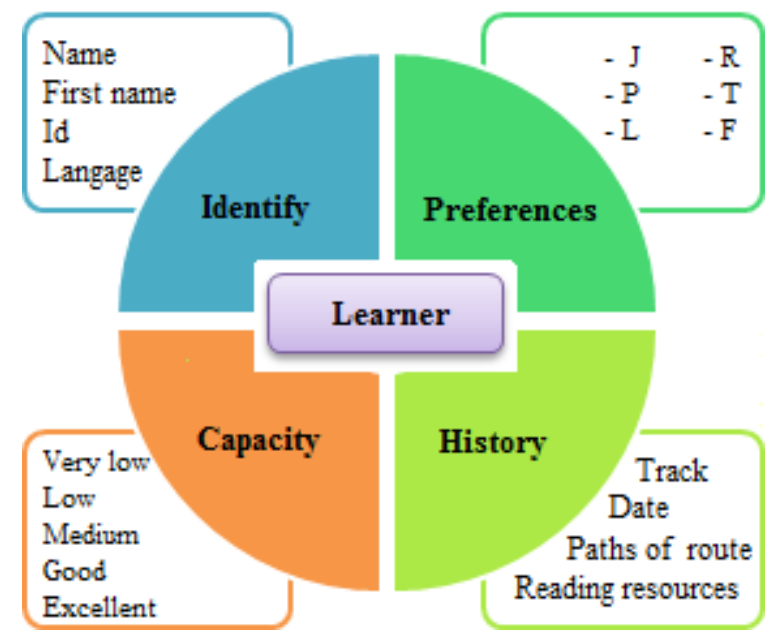

Fig.2. The four components of the ontology "Learner"

The sub-ontology "Identity" SOIdentity is responsible for representing the information about a particular user of a MOOC. It is composed of essential and common to all users predefined attributes: name, username, language, media type, etc.

The sub-ontology "Preferences" SOPreferences is responsible for representing the preferences of learning among MOOCs learners. This component is based on the theory of psychological types of MBTI. It describes the preferences of the learner as a vector of preferences. The latter is described as a conceptual vector $V_{\text {Preferences }}=\{\mathrm{Ep}$, Ip, Sp, Np, Tp, Fp, Jp, Pp $\}$. This vector is used to specify the MBTI psychological style of the MOOC learner and thus inform about these learning preferences.

The sub-ontology "Capacity" (knowledge) SOCapacity is responsible for representing or giving a knowledge level of a MOOC learner for a concept. This knowledge is modeled by a stereotype can be obtained with a level test (MCQs). Possible values are "very low", "low", "medium", "good" and "excellent". For example, levels of a learner $\mathrm{L}_{1}$ are described as follows: $\left\{\mathrm{L}_{1}\right.$, <"Network", "definition", "Medium"> <"Network", "description", "low"> <"OSI" , "example", "Medium"> \}.

The sub-ontology "History", SOHistory is responsible for keeping track of the status of the historic of a learner enrolled in MOOCs platform (memorizing the navigation and reading resources documents). This representation allows giving the date of the consulting of a resource or also the paths of route for the navigation order. For example, the path of the learner $\mathrm{L}_{1}$ is : $\left\{\mathrm{L}_{1}\right.$, <"Network", "definition", "01/12/15">, <"Network", "description", "10/12/15" > \}.

\section{Resource ontology}

The "Resource" model is defined as a $\mathrm{O}_{\text {Resource }}$ ontology including various characteristics of an educational resource used in a MOOC. This work proposes to describe a digital resource or content on two levels. These levels are described as Sub-Ontologies: OResource =
$\left\{\mathrm{SO}_{\text {Description }}, \mathrm{SO}_{\text {Category }}\right\}$ (Fig. 3).

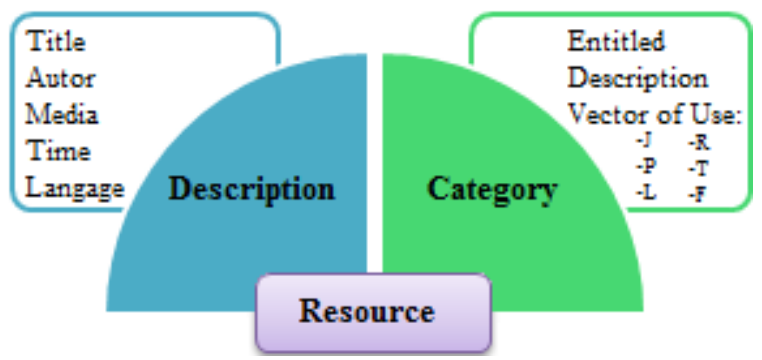

Fig.3. The two components of the ontology "Resource"

The first, SODescription, describes the educational characteristics of the resource (author, title, language, media, time, ...). The second, SOCategory, used to classify learning resources of a MOOC into different categories based on their content, their uses and purposes of such uses. Each category is described by a concept which consists of the following elements: a title, a descriptive, a vector of use. The latter is described as a conceptual vector $\mathrm{V}_{\mathrm{Use}}=\{\mathrm{Eu}, \mathrm{Iu}, \mathrm{Su}, \mathrm{Nu}, \mathrm{Tu}, \mathrm{Fu}, \mathrm{Ju}, \mathrm{Pu}\}$.

The conceptual vector of a learning resource of MOOCs allows specifying that his content is more suited (adequate) for a given learning style, so for a MBTI psychological style.

The allocation of settings of a resource of a MOOC is made by the designer knowing the content, purpose and possible use of this resource. This assignment is carried via an ergonomic interface masking the technical details when the testimony of a resource. Thereafter, the value of a vector of the use of a resource can be changed (adjusted) manually by the designer of the MOOC resource or automatically by the mutli-agents system based on traces of future uses of this resource by different learner profiles.

\section{Domain ontology}

The "Domain" ontology, $\boldsymbol{O}_{\text {Domain }}=\left\{\boldsymbol{S} \boldsymbol{O}_{\text {Computer science, }}\right.$ SOMathematics, $\boldsymbol{S} \boldsymbol{O}_{\text {Physics, }}$ etc.\}, describes the concepts of a domain of knowledge of the MOOC that correspond to an educational domain (mathematics, computer science, chemistry, law, etc.). We can have several domains ontologies, each being specific to a teaching discipline and she describes the different concepts. A concept is a unique notion of the domain of knowledge of a MOOC represented by a name. For example, the ontology of the domain of computer science includes the following concepts: database, programming languages, computer networks, etc.

\section{Pedagogical Strategies ontology}

The pedagogical strategy model is defined as an ontology, $\mathrm{O}_{\text {Strategies}}$, comprising all the models of teaching and learning (transmissive model, constructivist model, socioconstructivist model, etc..), the methods and approaches, which will determine the choice of techniques, materials and educational situations, relative to the object and the goal of learning of a MOOC. Teaching strategies can be chosen according to the learning style of the learner.

This work proposes to decompose the ontology 
"Strategy" into two sub-ontologies (SO), according to the Lasnier decomposition [35]: sub-ontology "Teaching strategies" and sub-ontology "Learning strategies": $\mathrm{O}_{\text {Strategies }}=\left\{\mathrm{SO}_{\text {Teaching, }}, \mathrm{SO}_{\text {Learning }}\right\}$.

The sub-ontology "Teaching strategies", SO Teaching, includes the masterful strategies (presentation, practical demonstration), individual work strategies (independent practice, individual work session, problem-based learning), interactive strategies (group discussion, role play, modelling, guided practice, learning by steps) and constructivist and socio-constructivist strategies (peer tutoring, mentoring, teamwork, cooperative learning, project-based learning, case studies).

On the other hand, the sub-ontology "Learning strategies", SOLearning, includes cognitive strategies (activation, acquisition, development, organization of knowledge, integration, transferring), affective strategies (reception, motivation, stress management, cooperation, conflict resolution) management strategies (time, material resources, human resources, environment) and metacognitive strategies (planning, monitoring, controlling and evaluating).

\section{B. Agents implemented}

The used ontologies generate two extensional agents: "Profile Management Agent" (PMA) and "Resources Builder Agent" (RBA). Each agent is implemented using a set of modules. Fig. 4 shows the architecture of the proposed model of MOOC environment integrating the multi-agents system allowing the adaptation of learning resources to learners' profiles.

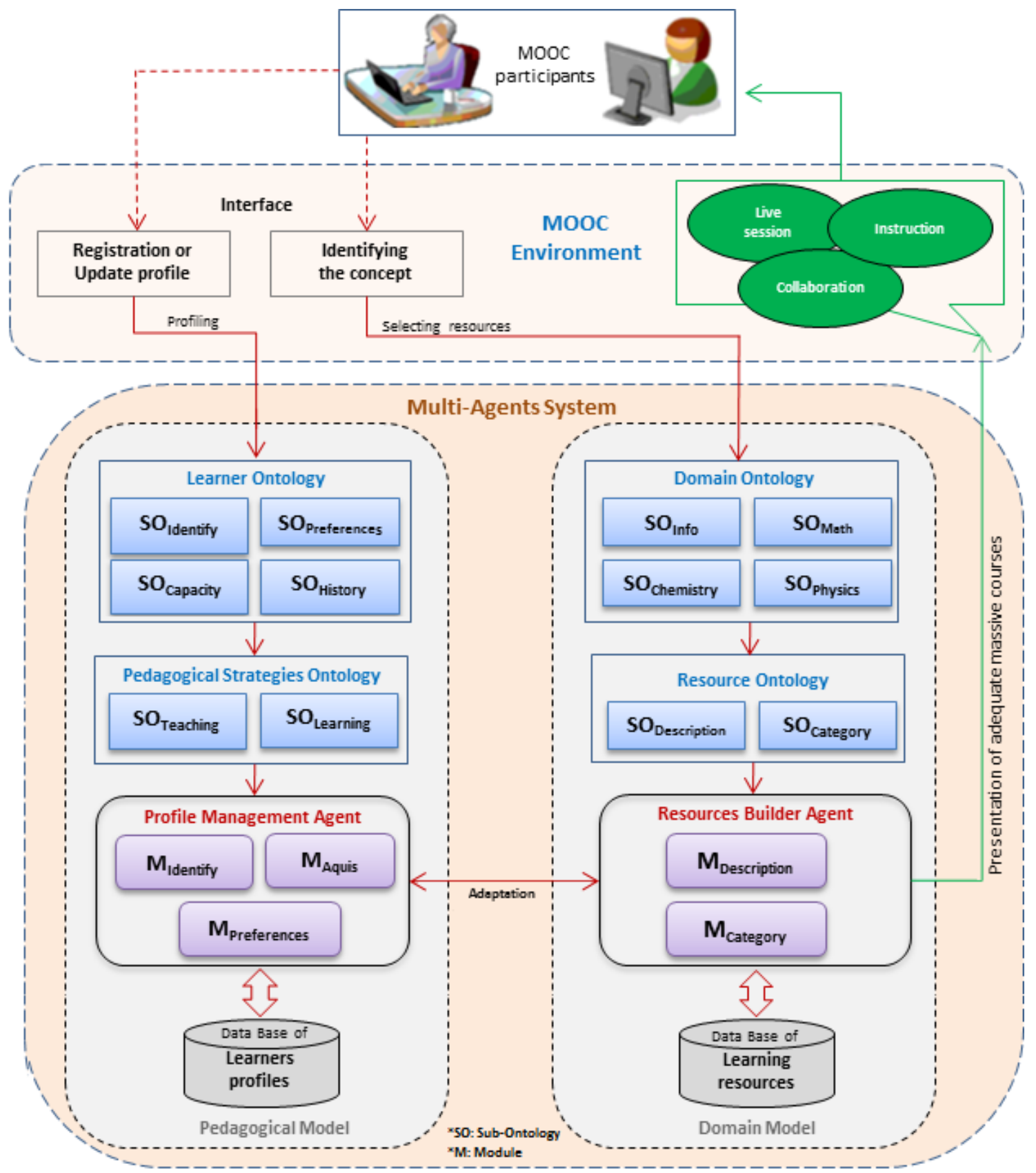

Fig.4. Architecture of the proposed model 


\section{Profile Management Agent (PMA)}

Profile Management Agent consists to determine the profile of learners according to their preferences. From the request formulated by the MOOC participant and sent through the graphical interface of the MOOC platform, PMA creates the learner profile by using the ontologies Learner Ontology and Pedagogical Strategies Ontology and the underlying ontologies. PMA store then the learner profile created in the data base of profiles to be used by the Resources Builder Agent. We also note that the Profile Management Agent allows to a MOOC participant already registered to update her profile.

\section{Resources Builder Agent (RBA)}

The Resources Builder Agent uses the Domain Ontology and Resource Ontology to select the adequate resources to use in a MOOC. Once it receives the request from the Profile Management Agent, the process of adaptation starts and takes in to account the learner profile and the concept in order to search and select contents that match the query and then to build the adapted MOOC.

\section{Functioning of the proposed model}

In the proposed model of MOOC environment integrating the multi-agents system, the process of generating of courses adapted to the learner profile, is performed in several phases:

\section{Profiling: PMA}

When registering a new learner, the Profile Management Agent (PMA) proposes him/her a questionnaire to determine his/her psychological type. After completing and validating the questionnaire, the PMA calculates and stores the result in the data base of learners profiles.

\section{Update of profile: PMA}

A MOOC participant already enrolled can update him/her profile by changing the values representing the level of knowledge and this for a number of resources of a given concept. In the Profile Management Agent, the historic, modeled with the sub-ontology SOHistory, will also evolve dynamically and automatically as and when the learner will follow new knowledge.

\section{Resources selection: RBA}

The learner connects to the MOOC system via a userfriendly interface allowing him to describe his request (search for resources, etc.). This request is described using concepts from the domain ontology ( $\left.\mathrm{O}_{\text {Domain }}\right)$ implemented in the Resources Builder Agent (RBA). The $\mathrm{RBA}$ is responsible for a pairing between the semantic of request and the semantic of contents and resources stored in the database and annotated by concepts coming from the ontology $\mathrm{O}_{\text {Domain. }}$ This pairing is accomplished by using a distance $\mathrm{D}_{\text {Content }}$ which compares the query structure with annotations of those resources.

\section{Adaptation: PMA-RBA}

The result of the previous step is a list of educational contents and resources $L_{\text {Content. The Multi-Agents System }}$ compares the semantics of resource uses from the list with the description of the learning preferences of the learner who submitted the initial request. This comparison is performed using a distance $D_{\text {use }}$ which calculates the distance (in the vectorial sense) between the vector $\mathrm{V}_{\text {Preferences, }}$ describing learning preferences of the MOOC participant, and the vector $\mathrm{V}_{\text {Use }}$ of usage of each resource.

\section{Presentation of adapted resources: RBA}

At the end of the previous two steps (selection and adaptation of resources), the Resources Builder Agent has a set of educational contents and resources which all correspond physically and semantically to the MOOC participant needs. A list $\mathrm{L}_{\mathrm{Use}}$ of adequate Massive Open Online Courses is then proposed to the learner. The latter made his choice among the items on this list as he/she may reject the entire list. The decision of the learner is stored in the system. Thus, further processing in the footsteps of online course of the learner can be exploited to refine the profile of learner or the descriptions of resources usages.

\section{CONCLUSION AND FURTHER WORK}

Finding the reasons behind the low rates of completion of MOOCs and identifying areas in which these can be improved is an important goal for MOOCs development. One factor which has been suggested as influencing dropout concerns the courses offered where their pedagogical contents and resources are not adapted to the learner profile.

This paper reports a model of multi-agents system based on ontologies and cognitive theories, to adapt educational resources to learners' profiles, especially their learning preferences. The multi-agents system is designed to be integrated in MOOCs environments.

In the proposed model, the process of profiling is based on the theory of psychological types of MBTI. The multiagents system includes two main agents (Profile Management Agent and Resources Builder Agent) revolve around four main ontologies (Learner ontology, Resource ontology, Domain ontology and Pedagogical Strategies ontology), they even composed of a set of subontologies. To lead learners to the completion of courses where they are enrolled, these agents are used to select the appropriate content and adopt a suitable strategy of teaching/learning.

As part of the continuity of this work, further research is underway to implement and integrate the model in a MOOCs platform in the form of complementary modules. On the other hand, we have planned to experiment the multi agents system in real conditions of learning with a restricted group of learners in the context of a MOOC. 


\section{REFERENCES}

[1] J. Daniel, "Making Sense of MOOCs: Musings in a Maze of Myth, Paradox and Possibility", Journal of Interactive Media in Education, vol. 3, 2012.

[2] D. Peterson, "The Pros and Cons of MOOCS", 2014. Available at: http://adulted.about.com/od/AdultEducation-in-the-U.S./a/The-Pros-And-Cons-Of-

Moocs.htm, [Accessed: 06/11/2015].

[3] C. Parr, "MOOC Completion Rates 'Below 7 \%"”, 2013. Available at: http://www.timeshighereducation.co.uk/news/mooccompletion-rates-below-7/2003710.article. [Accessed: 23/10/2015].

[4] K. Jordan, "MOOC Completion Rates: The Data", 2013. Available http://www.katyjordan.com/MOOCproject.html [Accessed: 06/11/2015]

[5] S. Kolowick, "Coursera Takes a Nuanced View of Mooc Drop-out Rates", 2013. Available at: http://chronicle.com/blogs/wiredcampus/coursera-takes-anuanced-view-of-mooc-drop-outrates/43341 [Accessed: 10/11/2015].

[6] D. F. O. Onah, J. Sinclair, and R. Boyatt, "Drop-out rates of Massive Open Online Courses: behavioural patterns", In Proceedings of the 6th International Conference on Education and New Learning Technologies, 7-9 July 2014, Barcelona, Spain.

[7] L. Pappano, "The Year of the MOOC", The New York Times, 2013.

[8] T. Lewin, "Universities Abroad Join Partnerships on the Web", New York Times, 2013.

[9] Wikipedia, "Massive open online course", 2015. Available

at:http://en.wikipedia.org/wiki/Massive_open_online_cou rse. [Accessed: 01/11/2015].

[10] M. Jenny, J. M. Sui Fai, and W. Roy, "The Ideals and Reality of Participating in a MOOC", In proceedings of Networked Learning Conference, 2010.

[11] Y. Tabaa, A. Medouri, "LASyM: A Learning Analytics System for MOOCs", International Journal of Advanced Computer Science and Applications, vol. 4, no. 5, 2013.

[12] OpenupEd (MOOC provider), "Definition Massive Open Online Courses (MOOCs)", Version 1.1, March 2015. Available

at: http://www.openuped.eu/images/docs/Definition_Massive _Open_Online_Courses.pdf [Accessed: 31/10/2015].

[13] J. Daniel, "Making sense of MOOCs: Musings in a maze of myth, paradox and possibility", Journal of Interactive Media in Education, vol. 3, 2012.

[14] L. Yuan, S. Powell and B. Olivier, "Beyond MOOCs: Sustainable Online Learning in Institutions", Centre for Educational Technology \& Interoperability Standards (Cetis), 2014. Available at: http://publications.cetis.org.uk/2014/898 [Accessed: 02/11/2015]

[15] R. Kop, "The challenges to connectivist learning on open online networks: learning experiences during a massive open online course", The International Review of Research in Open and Distance Learning, vol. 12, no. 3, 2011.

[16] K. Devlin, "MOOCS and Myths of Drop-out Rates and Certification", 2013. Available at: http://www.huffingtonpost.com/dr-keith-devlin/moocsand-myths-of-dr_b_2785808.html [Accessed: 08/11/2015].

[17] S. Cross, "Evaluation of The OLDS MOOC Curriculum
Design Course: Participant Perspectives and Experiences", OLDS MOOC Project, Milton Keynes, Available at: http://oro.open.ac.uk/37836/1/EvaluationReport_OLDSM OOC_v1.0.pdf [Accessed 10/11/2015]

[18] D. Yang, T. Sinha, D. Adamson P. C. Rose, "Turn on, Tune in, Drop out": Anticipating Student Drop-outs in Massive Open Online Courses", 2013. Available at: http://lytics.stanford.edu/datadriveneducation/papers/yang etal.pdf [Accessed: 31/10/2015]

[19] S. P. Balfour, "Assessing Writing In MOOCs: Automated Essay Scoring and Calibrated Peer Review", Research \& Practice in Assessment, vol. 8, no. 1, pp. 40-48, 2013.

[20] G. Fischer, "User Modeling in Human-Computer Interaction", User Modeling and UserAdapted Interaction, vol. 11, no 1-2, pp. $65-86,2001$.

[21] S. Abedinzadeh, S. Sadaoui, "A Rough Sets-based Agent Trust Management Framework", International Journal of Intelligent Systems and Applications, vol. 5, no. 4, pp. 119,2013

[22] C. Webber, L. Bergia, S. Pesty, N. Balacheff, "The Baghera project: a multi-agent architecture for human learning", Proceedings of the Workshop Multi-Agent Architectures for Distributed Learning Environments, AIED2001, San Antonio, TX, USA. pp. 12-17, 2001.

[23] P. Pavel, "GD.Visu@1 : Environnement Distribué Interactif pour l'Apprentissage Humain de la Géométrie Descriptive", Doctoral dissertation, Université du Maine, 1999.

[24] A. Bennane, T. D'hondt, B. Manderick and A. Now, "Pedagogical process management: A case study by applying the reinforcement learning", Journal Media and Communication Studies, vol. 1, no 3, pp. 48-55, 2009.

[25] A. Pedrazzoli, “OPUS One Ŕ OLAT (An Artificial Intelligence Multi Agent based Adaptive Learning Environment", Proceedings of the World Congress on Engineering and Computer Science, October 20-22, 2009, San Francisco, USA.

[26] G. Falquet, L. Nerima and J. Ziswiler, "Utilisation des ontologies dans les environnements d'écriture collaborative d'hyperlivres, expériences et perspectives". Revue Sticef, vol. 11, 2004.

[27] F. Azouaou, "Modèles et outils d'annotations pour une mémoire personnelle de l'enseignant", Doctoral dissertation, Université Joseph Fournier, France, 2006.

[28] C. Piombo, "Modélisation probabiliste du style d'apprentissage et application à l'adaptation de contenus pédagogiques indexés par une ontologie", Doctoral dissertation, IRIT, France, 2007.

[29] S. Sosnovsky, "Integration of Two Domain Conceptualizations in a Single Adaptive Hypermedia System", Workshop on Applications of Semantic Web Technologies for e-Learning (SW-EL@AH'06), 2006, Ireland.

[30] B. Castello, W. Neto, O. Alvaro et F. Gauthier, "Sharing and Reusing Information on Web-Based Learning", $S W$ EL@AH’06, June 21-23 2006, Dublin, Ireland.

[31] R. Morales, N. Van Labeke and B. Paul, "Towards a Learner Modelling Engine for the Semantic Web", $S W$ EL@AH'06, June 21-23 2006, Dublin, Ireland.

[32] A. Ounnas, I. Liccardi, H. Davis., D. Millard and S. White "Towards a Semantic Modeling of Learners for Social Networks”, SW-EL@AH’06, June 21-23 2006, Dublin, Ireland.

[33] C. R. Todd, "Myers-Briggs Type Indicator®", The Skeptic's Dictionary, 2004.

[34] A. Behaz, M. Djoudi, "Adaptation of learning resources based on the MBTI theory of psychological types", 
International Journal of Computer Science Issues, vol. 9, Issue 1, No 2, pp 135-141, 2012.

[35] F. Lasnier, "Réussir la formation par compétences", Montréal : Guérin, 2000.

\section{Authors' Profiles}

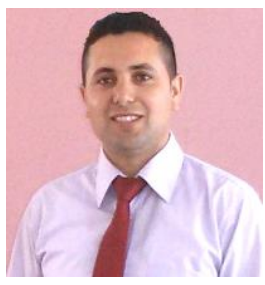

Abderrahim EL MHOUTI - received the $\mathrm{PhD}$ degree in Computer Science in 2015 in LIROSA laboratory and the Master degree in Software Quality in 2011 from Abdelmalek Essaadi University, Faculty of Sciences, Tetouan, Morocco.

Dr. EL MHOUTI is a Professor of Computer Science at the secondary cycle since 2006. His research fields include : collaborative e-learning and pedagogy, Web 2.0 technologies and cloud computing. He has published several articles on e-learning, Web 2.0 and educational technologies.

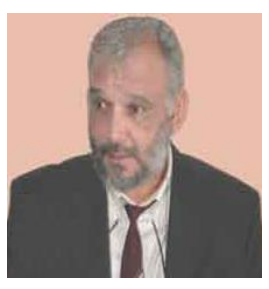

Azeddine NASSEH - received the PhD degree from the Free University of Brussels in Belgium. He is Professor and computer science researcher. $\mathrm{He}$ is member of LIROSA laboratory. His areas of interest include: e-learning and pedagogy, MOOCs, and Web 2.0.

Prof. NASSEH is currently a full Professor of computer science and head of Management and Computer Science Department at Ecole Normale Supérieure, Abdelmalek Essaadi University, Tetouan, Morocco. He has published several articles on E-learning and Web 2.0 technologies.

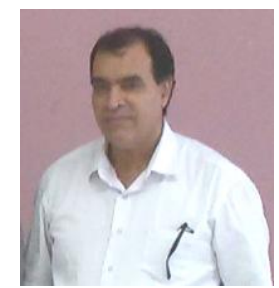

Mohamed ERRADI - received the $\mathrm{PhD}$ degree from the Mohammed V University in Morocco. He is Professor and computer science \& pedagogy researcher. $\mathrm{He}$ is member of LIROSA laboratory. His research fields are: elearning, pedagogy, and educational technologies.

Prof. ERRADI is currently Professor and pedagogy trainer at Ecole Normale Supérieure, Abdelmalek Essaadi University, Tetouan, Morocco. He has published several articles on elearning and educational technologies.

How to cite this paper: Abderrahim El Mhouti, Azeddine Nasseh, Mohamed Erradi, "Stimulate Engagement and Motivation in MOOCs Using an Ontologies Based MultiAgents System", International Journal of Intelligent Systems and Applications (IJISA), Vol.8, No.4, pp.33-42, 2016. DOI: 10.5815/ijisa.2016.04.04 